\title{
Amós, deshumanización y comunidades desplazadas
}

\author{
Aquiles Ernesto Martínez, \\ Reinhardt University, \\ Waleska, GA
}

\section{Introducción}

En el último tercio del siglo XX el libro de Amós cobró gran notoriedad en América Latina y el Caribe, y más tarde, como consecuencia de ello, en otros países ${ }^{1}$. Fue un hito importante en la historia de la interpretación de la Escritura. En las cátedras de teología, en la literatura tanto especializada como popular, incluso en muchas homilías dominicales, y en estudios bíblicos, se prestó mucha atención a cómo, a mediados del siglo VIII antes de Cristo, en tiempos de la monarquía israelí antes de su división en dos reinos, este profeta defendió los derechos de los pobres al criticarlos abusos cometidos contra ellos por los ricos de Israel.

El significado actual de este profeta fue redescubierto $-\mathrm{y}$ cobró mayor fuerza- al surgir una visión de la realidad del mundo sensible a la situación de pobreza en la que vive la mayoría de sus habitantes. Esa nueva visión ayudó a entender "el mensaje de Dios" más allá del momento histórico en el que se escribió el libro de Amós, pero también ayudó a comprender nuestro mundo a partir de su mensaje.

Al pensar qué puede significar el mensaje de Amós en el quehacer teológico de las iglesias de hoy, hay que tener en cuenta que la realidad social ha cambiado muy poco entre el siglo pasado y el presente. La opresión de los pobres no solo no ha disminuido, sino que se ha recrudecido y ha adquirido nuevos rostros

1 Esto independientemente de que el profeta Amós ocupa un lugar privilegiado en la literatura profética del Antiguo Testamento. Ver J. M. Ward, "Amos, Oseas", en J. H. Hades (ed.), Knox Preaching Guides, Atlanta: John Knox Press, 1981, p. 1; T. J. Finley, "An Evangelical Response to the Preaching of Amos", Journal of the Evangelical Theological Society, 28 (1985), pp. 411-420. 
- solo que ahora ocurre dentro del marco socioeconómico de "la globalización". Las políticas neoliberales del mercado mundial se nutren de la avaricia expansionista y del sometimiento de los pueblos, a lo cual cabe agregar los gobiernos que privan de libertad a las mayorías, el terrorismo, el discurso desgastado de una izquierda arbitraria, excluyente e institucionalizada, y las nuevas élites. Todos ellos son responsables de esta renovada situación de injusta penuria y abuso de las mayorías. Esta situación ha creado una inestabilidad social, política y económica, que ha obligado a un sinnúmero de personas a emigrar diariamente, dentro y fuera de las fronteras de sus propios países, para buscar una vida mejor. Pero ahí a donde llegan son maltratadas, aunque en contextos de opresión, resultado de la dispersión. Los cada vez más numerosos y brutales conflictos armados, la violencia ciudadana ciega y, en menor escala, los desastres naturales han generado efectos similares. Algo parecido le sucedió al pueblo judío, a Jesús y a la Iglesia primitiva ${ }^{2}$.

En esta nueva realidad social, hablar de pobreza, explotación y opresión es también hablar de comunidades desplazadas y obligadas a vivir en cautiverio diáspora, se trate de migrantes en general, de buscadores de asilo o de refugiados. En una situación de "falta de "o de "dislocamiento", sin importar cómo sean definidas y dónde y cómo ocurran, siempre habrá visionarios apasionados con los pies en la tierra que, al igual que Amós, denuncien las causas, los factores influyentes, sus expresiones concretas y las secuelas devastadoras, todo para generar "conciencia" como primer paso para atenuar, sino erradicar, situaciones infrahumanas. En la América de hoy, muchos teólogos y biblistas han comenzado a reflexionar hermenéuticamente sobre esta realidad, triste e inescapable ${ }^{3}$.

Ahora bien, nuestra concepción del mundo cambia con el paso del tiempo. El concepto de pobreza, resultado de la opresión y la explotación, no solo varía, sino que cada cultura lo piensa de manera diferente. De ahí que siempre sea

2. Sobre estos temas y desde un punto de vista bíblico y pastoral, ver mis trabajos $E l$ hogar fuera del hogar: diáspora, comunidad y ministerio, Nueva York: Mi Familia Center y Plan Nacional para el Ministerio Hispano-Latino, 2012 (material publicado con circulación limitada); Interpretación bíblica con sabor latino: una invitación al diálogo desde la diáspora, Caracas: Mi Familia Center y Acción Ecuménica, 2012; "I was a stranger and you took me in". Immigration and the Christian Community (inglés y español), Nashville: General Board of Discipleship, 2009; "Mordecai and Esther: Migration Lessons from Persian Soil", Journal of Latin American Theology, 4, 1 (Spring 2009), pp. 16-50; “The Immigration Controversy and Romans 13: 1-7”, Apuntes: Reflexiones teológicas desde el margen hispano, 27, 4 (Winter 2007), pp. 124-144; "On Sheep and Goats: The Treatment of Foreigners According to Jesus (Matthew 25: 31-46)", Journal of Hispanic/Latino Theology (2007); "Jesus, the Immigrant Child: A Diasporic Reading of Matthew 2: 1-23", Apuntes, 26, 3 (Fall 2006), pp. 84-114.

3. Ver, por ejemplo, el número 63 de la revista Ribla. 
necesario "revisar" el mensaje de Amós sobre la pobreza, pero a la luz de las nuevas formas de entender lo que significa vivir con poco o nada. Hablar de este tema hoy en día, en el contexto del desplazamiento forzado de personas y su consecuente maltrato, es una invitación a hablar de la condición de "personas en movimiento". Esto es, de millones de personas, en su gran mayoría pobres, campesinos, indígenas o trabajadores, que viven en una tierra extraña y a las que se les trata como extrañas. Hablar de pobreza es, entonces, hablar de la falta de hospitalidad y de diversas formas de abuso y violencia, en ambos lados de las fronteras y entre las fronteras. El libro de Amós puede, y debe, analizarse desde la migración como tal y desde el empobrecimiento que genera en los países de origen, de tránsito y de destino. Sorprendentemente, estas realidades han sido pasadas por alto incluso en la literatura reciente sobre el libro de Amós ${ }^{4}$. Por lo tanto y en aras de la diversidad de lecturas, conviene contextualizar nuestra interpretación del profeta.

Tras estas observaciones previas, a continuación reflexionaré sobre el mensaje histórico del libro de Amós, pero a la luz de las experiencias de las multitudes que siguen siendo obligadas a trasladarse a otras tierras por la explotación y la opresión de las cuales han sido víctimas en su hogar de origen y que prosiguen en su nuevo hogar. Pienso que reinterpretar a Amós desde esta perspectiva tiene mucho que enseñarnos, tanto a nosotros como al profeta. Pero antes hay que refrescar nuestro conocimiento de las causas y las manifestaciones históricas que concretan la opresión de los pobres en Israel, en tiempos del oráculo del profeta Amós. Y cómo este vocero analiza y responde a esa realidad con una palabra de juicio contra los opresores, pero también con palabras de solidaridad, justicia y esperanza para las víctimas de salvajes abusos de poder ${ }^{5}$.

\section{Perfil de un vocero solidario, que se mueve al margen de los deten- tadores del poder}

La teología, como expresión de la fe en Dios, de posturas ideológicas y de decisiones éticas, siempre tiene carácter biográfico. Es decir, está vinculada a las experiencias de la vida. En el caso de Amós y de su contexto vital, hay varios

4. Ver P. R. Andiñach, "Amós: memoria y profecía. Análisis estructural y hermenéutica”, Revista Bíblica, 45 (1983), pp. 209-301; J. R. Arango L., "Opresión y profanación del santo nombre de Dios. Estudio del vocabulario de Am 2, 7b", Ribla, 11 (1992:1), pp. 49-63; S. Gallazzi, "El diezmo y la falta de pan y de justicia (Amós 4, 6 y Lucas 18, 12)", Ribla, 51 (2005: 2), pp. 27-36; H. Reimer, "Agentes y mecanismos de opresión y explotación en Amós", Ribla, 12 (1992: 2), pp. 69-81; idem, "Amós: Profeta de juicio y justicia”, Ribla, 35-36 (2000:1-2), pp. 153-168; M. Schwantes, "Jacob, el pequeño. Visiones en Amós 7-9", Ribla, 1 (1988:1), pp. 87-99.

5. Un buen resumen de estas realidades en J. R. Arango, "Opresión y profanación del santo nombre de Dios", op. cit., pp. 49-63. 
indicadores de prosopografía que apuntan a una realidad de "movimiento" y "marginalidad". Esta realidad hace que su mensaje sea congruente con su experiencia y relevante para los desafíos de la realidad histórica en la que vivió.

El libro de Amós abre sus páginas con la identificación de su autor $(1,1)$. Su nombre es Amós, transliteración del término hebreo sAm[', que significa "llevado" o "cargado por Dios", y que, por extensión, define bien su misión. ¿Pero enviado adónde? Al considerar el libro desde una perspectiva comunicacional amplia, Dios envía al profeta a proclamar un mensaje de juicio y justicia al pueblo israelita ya otras naciones, pero especialmente al reino del norte, Israel.

No obstante, no es accesorio señalar que su oficio y su lugar de residencia presentan a este profeta como una persona familiarizada con el libre movimiento y las típicas experiencias de exclusión. Amós fue "pastor", o más precisamente, alguien dedicado a criar ovejas y a comerciar con ellas ( $c f$. 2Re 3,4$)$, al igual que cultivador de sicomoros ${ }^{6}$, es decir, también fue campesino. Pero esto no es todo. Vivió en la periferia, en la aldea de Tecoa, localizada posiblemente a unos veinte kilómetros al sur de Jerusalén, la capital del reino del sur?

Asimismo, la vocación religiosa de Amós parece haber sido fuera de lo común, pues se compagina con la naturaleza radical de su profecía. Se cree que este personaje no perteneció al orden profético tradicional e institucionalizado, sino que fue más bien un "profeta laico" de orígenes humildes, escogido para hacer sentir la voz de Dios contra el reino del norte ${ }^{8}$, según lo revela su disputa contra el sacerdote Amasias, en Betel (cf. 3, 1-8; 7, 14.15)9.

Su individualidad se destaca mucho más si la cotejamos con la tradición profética del siglo VIII a.C. y con el contexto en el cual le tocó vivir. Siendo quizá el más antiguo de los profetas de esa época - junto con Oseas, Isaías y Miqueas-, el ministerio de Amós tiene lugar en medio de una crisis social,

6. En Amós 1, 1 (cf. 2Re 3, 4) no aparece la palabra hebrea típica que designa al pastor de ovejas (roeh). El término usado allí es dqenO, que significa "criador de ovejas" o "comerciante de ovejas". En 7, 14 se usa rqeAB, que probablemente designa a la persona que hace que el ganado se reproduzca. Esto pareciera sugerir que Amós no era solo un "pastor pobre", sino un pequeño comerciante. También J. G. Bailey, "Amos: Preacher of Social Reform", The Bible Today (1981), pp. 306-307.

7. E. Hammershaimb, The Book of Amos: a Commentary, New York: Schocken Books, 1970, p. 11.

8. H. H. Mallau, "Las reacciones frente a los mensajes proféticos y el problema de la distinción entre profetas verdaderos y falsos. A propósito de Amós 7, 10-17”, Revista Bíblica, 34 (1972), pp. 33-39.

9. H. Hammershaimb, The Book of Amos, op. cit., p. 11, aunque existen divergencias en torno a este asunto, $c f$. J. M. Ward, "Amos, Oseas", op. cit., p. 2; A. Álvarez Valdés, "El enfrentamiento entre profetas y sacerdotes", Revista Bíblica, 53 (1991), pp. 221-223. 
política, moral y religiosa, en tiempos de Uzías, rey de Judá, y de Jeroboam II, hijo de Joás, rey de Israel, dos años antes de un terremoto no identificado, que sacudió la zona $(1,1)^{10}$. Estos detalles sitúan al pequeño gran profeta, probablemente, al final del período de estos reyes, entre 780 y 740 a.C..$^{11}$, es decir, aproximadamente, en 760 a.C. Esto es, antes de que el reino del norte entrara en confrontación con Asiria y aquel fuera destruido esta, en 721 a.C.' ${ }^{12}$. Entonces, muchos habitantes de Israel fueron deportados a tierra extraña, mientras que otros decidieron emigrar al sur, al reino de Judá.

Aparte de estos datos que nos ayudan a aproximarnos al mensaje de Amós y a su opción por una vida ministerial, ¿qué más podemos decir para situar la fe y el trabajo de este vocero de Dios y del pueblo oprimido con vistas a reflexionar sobre la realidad actual de migraciones obligadas?

\subsection{La opresión en Israel: causas, síntomas y mucho más}

En el Antiguo Testamento, "la profecía" jamás surge de la nada o se da en el vacío, sino que ocurre en un contexto particular y como respuesta a él. Y aunque a veces ese contexto no está del todo claro o accesible, siempre es posible una visión panorámica y acertada. Pero para ello es necesario recurrirá otras fuentes de información, que nos permitan reconstruir un "escenario contextual de lectura", por muy tentativo e incompleto que sea. Es así como abordamos a Amós.

En primer lugar, se sabe muy poco sobre la administración del Estado de Israel, en tiempos del rey Jeroboam II, el siglo VIII a.C. ${ }^{13}$. Aparte de señalar que este monarca "hizo lo malo ante los ojos de Yahvé", una referencia a la promoción de la idolatría y los pecados afines, el redactor del libro segundo de los Reyes no suministra información sobre la situación del Israel de esa época. Sin embargo, es posible hacerse una idea general.

En los 41 años del mandato de Jeroboam II, Israel gozó de relativa estabilidad política ${ }^{14}$. El enfrentamiento armado con los países vecinos desapareció. Adadnirari III, rey de Asiria, sometió a Damasco, el vecino más peligroso al

10. Sobre este incidente no existe evidencia histórica definitiva que ayude a ubicar la profecía de Amós. Es probable que Zacarías 14, 5 sea una alusión al siniestro. $C f$. A. G. Auld, Amos, Sheffield: JSOT Press, 1986, p. 13; J. M. Ward, "Amos, Oseas", op. cit. p. 3; Y. Gitay, "Amos", en M. Eliade (ed.), The Encyclopedia of Religion, vol. 1, New York: McMillan Publishing Company, 1987, p. 240.

11. A. G. Auld, Amos, op. cit., p. 13.

12. R. Martin-Achard, God's People in Crisis: a Commentary on the Book of Amos, Grand Rapids: Eerdmans, 1984, p. 3.

13. J. Bright, La historia de Israel, Bilbao: Desclée De Brouwer, 1970, p. 310; F. I. Andersen y D. N. Freedman, "Amos”, The Anchor Bible, New York: Doubleday, 1989.

14. Y. Gitay “Amos”, op. cit., p. 240. 
norte de Samaria, y le impuso una enorme carga tributaria. Este hecho trajo algo de tranquilidad a Israel. Por otro lado, Asiria no representaba todavía una amenaza, pues estaba ocupada en derrotar a sus enemigos cercanos, en las áreas de Mesopotamia, Ararat y Media. Luego, entró en un período de relativa decadencia, que pospuso su consolidación como imperio mundial bajo la guía de Tiglath-Pileser III, que habría de someter a Israel. La reducción del peligro geopolítico al mínimo, o al menos suspendido temporalmente, permite a Jeroboam II expandir su dominio territorial hasta llegar casi a controlar la extensión de los reinados de David y Salomón (cf. 2Re 14, 23-29; 13, 24-25): "É1 [Jeroboam II] restableció las fronteras de Israel desde la Entrada de Jamat hasta el mar de Arabá, según la palabra de Yahvé, Dios de Israel, había dicho por boca de su siervo el profeta Jonás, hijo de Amittay, el de Gat de Jéfer" (2Re 14, 25).

El control de este extenso territorio y la paz reinante permitieron implementar políticas administrativas que redundaron en bonanza económica, sobre todo, para el Estado. La producción agrícola aumentó y se recuperó el control del comercio caravanero norte-sur que, al pasar por el territorio israelita, llena las arcas del Estado. Estas actividades permitieron el surgimiento de una nueva élite, rica, poderosa y ambiciosa, y la estructuración de una sociedad estratificada. En la cúspide de la pirámide social se encontraba una minoría egoísta, mientras que en su base se situaban las mayorías campesinas y empobrecidas ${ }^{15}$.

El desarrollo económico y político, tal como suele ocurrir en gobiernos muy centralizados y ricos, no propició el desarrollo social. "El querer tener más" desplazó a Dios y se convirtió en el nuevo ídolo del pueblo. Por consiguiente, la brecha que separaba a la clase alta de la clase baja se convirtió en un abismo. Los ricos acumulan privilegios, poder y recursos a expensas de la capacidad productiva de las masas. Esta organización social impide que las mayorías mejoren su calidad de vida y asciendan socialmente en la pirámide socioeconómica. Aquella era una sociedad polarizada de corte esclavista ${ }^{16}$, que aceptó gustosa la crisis moral y espiritual. Entonces, la corrupción y la injusticia hicieron su morada en ella ${ }^{17}$. Las raíces del mal se remontan al tipo de gobierno adoptado siglos atrás.

15. J. M. Ward, “Amos, Oseas”, op. cit. p. 3; A. Álvarez Valdés, "El enfrentamiento entre profetas y sacerdotes", op. cit., p. 223.

16. El sector medio de la población estaba casi extinto. Ver J. G. S. S. Thomson y J. A. Motyer, "Amos, Book of", The Illustrated Bible Dictionary, vol. 1, Willard, Ohio: Donnelley \& Sons Co., 1980, pp. 44-45; R. K. Harrison, “Amos”, en M. C. Tenney (ed.), The Zondervan Pictorial Encyclopedia of the Bible, vol. 1, Grand Rapids: Zondervan Publishing House, 1975, pp. 143-144.

17. Es probable que la clase alta de Israel se haya desviado y haya incurrido en la corrupción moral por su adhesión al culto cananeo a Baal. Descubrimientos arqueológicos indican que esta era una de las religiones más inmorales del cercano oriente (R. K. Harrison, "Amos”, op. cit., p. 143). 
Recordemos que Israel abandonó el liderazgo de Dios, a través del sistema tribal, y adoptó la monarquía sin considerar las consecuencias negativas del cambio $c f .1 \mathrm{Sm} 8,1-22)$. El desbarajuste de la nación era de índole estructural. De hecho, había sido anunciado y era irreversible. En el corazón del pueblo no había lugar para Dios, sobre todo, en la clase dirigente.

Un detalle importante es el sector social que se lleva la peor parte de la crisis. Los pobres, las víctimas explotadas de la nueva clase privilegiada anti-dios, no eran solo originarios de Judá, sino que más bien constituyen un grupo mixto. La deportación de muchos de sus habitantes a consecuencia de la caída del reino del norte, en 721 a.C., en manos de Asiria, no fue la única "migración forzada". La invasión extranjera (antes y después) obliga a muchos campesinos del reino del norte a desplazarse hacia el sur, al reino de Judá. De esta manera, los pobres que Amós defiende, los explotados por la nueva burocracia real, incluían a los desterrados, a otros forasteros residentes en el área y a los campesinos residentes de Judá ( $c f .2 \mathrm{Cr} 2$, 17; 30, 25; $c f .2 \mathrm{Sm} \mathrm{1,13;11,6-13).} \mathrm{Así,} \mathrm{pues,} \mathrm{la} \mathrm{designación} \mathrm{de}$ "pobres" comprende mucho más que una simple generalidad. Incluye también a los expulsados o desterrados.

En una sociedad tan estratificada y en la bancarrota espiritual, Amós no cierra los ojo, ni guarda silencio, ni se resigna impotente. Sino que ataca la crisis y denuncia, en primer lugar, una situación general de pecado. Según él, consciente y sostenidamente, Judá, al igual que sus ancestros, ha transgredido la ley mosaica $(2,4)$. Padres e hijos, símbolos de la rebeldía de ese pueblo, mantuvieron relaciones incestuosas con jóvenes doncellas, con lo cual corrompieron la institución de la familia y ofendieron a Dios $\left(2,7\right.$; $c f$. Dt 22, 28-29) ${ }^{18}$. Al igual que muchas de las naciones vecinas, practicaron "la idolatría" $(2,8 ; 3,14 ; 5,26 ; 7,9)$, obligaron a "los nazareos" a violar sus votos de abstinencia e impidieron que los profetas cumplieran con su tarea de profetizar $(2,12)$. Amós mismo fue víctima de las amenazas de Amasías, quien en representación de una religión institucionalizada al servicio de los intereses de la corona, le exigió no profetizar en su contra $(7,10-17)$. Pero este hombre de Dios, leal a su vocación, consciente de su identidad y en contravención de la intromisión del prelado, insistió en hablar "la Palabra de Dios", sin que le importaran las consecuencias. Un profeta verdadero no se deja intimidar y proclama lo que los demás no quieren escuchar. No es "el secretario ejecutivo" de ninguna burocracia.

Pero el rostro más repugnante de la crisis del sistema monárquico fue la explotación y la opresión de la clase subalterna, a manos de una nueva élite política-religiosa, para la cual el amor al dinero se convirtió en "el gran soberano". Entonces, Amós no vacila en atacar al dios del dinero y la gran vida que

18. J. R. Arango, “Opresión y profanación del santo nombre de Dios”, op. cit., pp. 49-63. 
este concede a sus adoradores a expensas de los pobres y desplazados ${ }^{19}$. Los culpables son tanto el Estado tributario (representado por el ejército, la religión oficial y el sistema judicial) como los israelitas, en concreto, sus relaciones económicas ${ }^{20}$.

Ahora bien, antes que desenmascarar todos los mecanismos que crean y mantienen esta situación de injusticia idolátrica, Amós concentra su crítica aguda en los síntomas de la crisis social ${ }^{21}$. En primer lugar, el profeta señala directamente a "la clase dirigente "del pueblo como la gran responsable de esa realidad deshumanizante y pone en evidencia sus crímenes, "los que pisan la cabeza de los débiles, y el camino de los humildes tuercen" (2, 7; cf. 8, 4), “Ay de los que cambian en ajenjo el juicio y tiran por tierra la justicia!" $(5,7)$. En su furor,

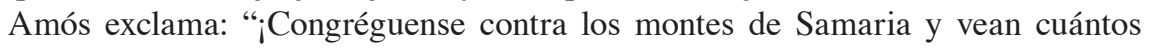
desórdenes en ella, cuántas violencias en su seno!" $(3,9)$.

Mas darse por enterado no es suficiente. El profeta nos da ejemplo al ser consciente de la problemática que debe contrarrestar. No así los ricos y los poderosos que, cegados por el dinero, permanecen en la indiferencia y en la insensibilidad ante la vida paupérrima de los débiles. Su necesidad contrasta fuertemente con el confort y el placer extremos de una clase alta hambrienta de recursos económicos, de poder y de privilegios. El hedonismo existente es patente $(3,12.15 ; 4,1 ; 5,11 ; 6,1 ; 8,3)$. Esta contradicción acentuaba la gravidez del pecado de la dirigencia. Amós ataca la suntuosidad anti-dios de los acaudalados y su encallecida insensibilidad ante sus presas indefensas.

${ }^{4}$ Acostados en camas de marfil, arrellenados en sus lechos, comen corderos del rebaño y becerros sacados del establo, ${ }^{5}$ canturrean al son del arpa,

se inventan, como David, instrumentos de música,

${ }^{6}$ beben el vino en copas, con aceite exquisito se ungen

mas no se afligen por el desastre de José $(6,4-6)$.

"Los dones" otorgados por la bonanza del Estado fueron evidentes. Sus beneficiarios gozaban de lujosas casas de verano e invierno $(3,15)$. Las primeras privilegiadas con este estado de "bendición" eran las doncellas reales. Por eso, el

19. J. L. Sicre, Los dioses olvidados: poder y riqueza en los profetas pre-exílicos, Madrid: Cristiandad, 1979, pp. 109-116.

20. Ver H. Reimer,"Agentes y mecanismos de opresión y explotación en Amós”, op. cit., pp. 69-81.

21. J. G. Bailey, “Amos: Preacher of Social Reform”, op. cit., p. 309. 
profeta considera que ellas también han pisoteado la dignidad de los pobres. Solo pensaban en sus deleites y el derroche. Irónicamente, las compara con las gordas "vacas de Basán" y también les promete juicio $(4,1)^{22}$.

La riqueza de Israel, según Amós, no ha sido generada por medios justos o éticos. Además de ser resultado del control de los medios de producción, es producto del saqueo y la trampa $(2,7 ; 3,9-10 ; 4,1.6 ; 8,4-6)$, de la imposición de pesadas cargas tributarias $(5,11)^{23}$ y del elevado precio de los alimentos de consumo diario. Todo ello expresión del "egoísmo" y de la "arrogancia" (6, 8.13; $c f$. v. $2 ; 9,10)$. Los ricos vendieron y compraron a "el justo" como si fuera mera mercancía para despojarlo de sus tierras, aun cuando la ganancia fuera poca ${ }^{24}$. Hoy, al igual que ayer, el amor al dinero es "la raíz de todos los males". Es insaciable y no considera las motivaciones, ni las consecuencias.

${ }^{4}$ Escuchen esto los que pisotean al pobre

y quieren suprimir a los humildes de la tierra,

5diciendo: “¿cuándo pasará el novilunio

para poder vender el grano,

y el sábado para dar salida al trigo,

achicando la medida y aumentando el peso,

falsificando balanzas de fraude,

${ }^{6}$ comprando por dinero a los débiles

$\mathrm{y}$ al pobre por un par de sandalias

falsear las balanzas

para vender hasta las ahechaduras del grano?" (8, 4-6).

El sistema judicial siempre favorecía a la clase alta, sobre todo, en el litigio de tierras. Su control era total. Los jueces aceptaban el soborno y, por lo tanto, sus fallos judiciales favorecían a los ricos que los protegían $(5,10.12 ; 6,12)^{25}$. El fraude y la extorsión fueron sus mejores aliados ${ }^{26}$ — "Que yo sé que son muchas

22. W. R. Harper, A Critical and Exegetical Commentary on Amos and Hosea, Edinburgh: T. \& T. Clark, 1973, p. 86.

23. Y. Gitay, "Amos", op. cit., p. 240; ibid., p. 120.

24. A. G. Auld, Amos, op. cit., p. 13; J. G. Bailey, "Amos: Preacher of Social Reform", op. cit., p. 309. No obstante, cabe destacar que esta expresión puede ser señal de un acuerdo o transacción comercial ( $c f$. Rut 4, 7) (B. Lang, "The Social Organization of the Peasant Poverty in Biblical Israel", Journal for the Study of the Old Testament, 24 [1982], p. 57).

25. W. R. Harper, A Critical and Exegetical Commentaryon Amos and Hosea, op. cit., p. 120.

26. "Extorsión" es una posible acepción de la voz amac (opresión), en su forma verbal y sustantiva, sobre todo, si se toma en cuenta la especificidad que adquiere a la luz del contexto del libro. $C f$. F. Brown, S. R. Driver y C. A. Briggs, A Hebrew and English Lexicon of the Old Testament, Oxford: Clarendon Press, 1979, pp. 798-799. 
sus rebeldías y graves sus pecados, opresores del justo, que aceptan soborno y atropellan a los pobres en la Puerta!" $(5,12)$. En una situación de semejante corrupción era natural que la libertad de expresión fuera anulada, a menos que se estuviera dispuesto a sufrir las consecuencias. "Por eso el hombre sensato se calla en esta hora, que es hora de infortunio" $(5,13)$. El temor se apodera del oprimido e intensifica su vulnerabilidad. De esta manera, la sociedad campesina era expropiada. La situación es muy similar a la de las mayorías de los países del tercer mundo y a la de los que emigran al primer mundo solo para ser oprimidos otra vez.

Ciertamente, la clase alta vivía engañada. Estaba convencida de que Yahvé la había bendecido de manera especial por haber sido seguidora y practicante "fiel" de la liturgia tradicional, lo cual era suficiente. De ahí su escrupulosidad en la observancia de los sacrificios y las ofrendas, según lo establecido por la ley mosaica $^{27}$. Pero Amós juzga que esa manera de acercarse a Dios era una burla, no solo porque significaba someterse a la religión cananea, sino que también por no ser consecuente con la moralidad y las relaciones humanas prescritas por la misma ley mosaica $(2,8 ; 4,4-5 ; 5,23 ; 8,5.10)$. No era un problema de falta de información, sino de compromiso. Dios rechaza esta falsa espiritualidad por ser incoherente con la ética.

${ }^{21}$ Yo detesto, aborrezco sus fiestas,

no gusto el olor de sus reuniones.

${ }^{22}$ no me complazco en sus oblaciones,

ni miro a sus sacrificios de comunión de novillos cebados (5, 21-22).

Estos indicios, derivados del contexto histórico-social y del mismo Amós, parecen apuntar a una forma temprana de lo que algunos expertos llaman "capitalismo rentista". Los puntos de contacto son impresionantes y nos llevan a concluir que la crisis de Israel era también de corte estructural. Según esta interpretación, (1) el campesino no era granjero o hacendado, sino que trabajaba para mantener a su familia; (2) el campesinado no conformaba una sociedad acabada e independiente, sino que formaba parte de una realidad mayor, integrada también por la élite educada y comerciante que, por lo general, residía en los pueblos y controlaba los asuntos públicos, y (3) la clase dirigente recaudaba impuestos entre los campesinos o exigía una parte de la producción agrícola. La relación entre "los señores de las zonas urbanas" y "los pobladores de las zonas campesinas" reviste, por lo general, la formalidad del libre comercio, en desventaja de estos últimos.

En este modo de producción económica, había tres clases de pacto, que definían las relaciones sociales entre las partes: el del patronato, el de la sociedad y el de la explotación. En el primer caso, el patrón se comprometía a proteger al

27. J. G. Bailey, "Amos: Preacher of Social Reform", op. cit., p. 309. 
campesino y a su familia a cambio de una parte de la cosecha. En el segundo, ambas partes acordaban repartirse de manera proporcional las ganancias obtenidas. Pero en el tercer caso, dado que el campesino estaba endeudado con su "señor" y que se excluía cualquier clase de protección, no había reciprocidad $\mathrm{y}$, virtualmente, este último se apoderaba de la tierra ${ }^{28}$. Las relaciones eran asimétricas.

Aparentemente, en la época de Amós predominaba este tipo de pacto, puesto que (1) dirige su mensaje a la élite urbana y comercial, que vive en el lujo y la extravagancia; (2) la tierra es cultivada por pequeños propietarios duramente explotados por los terratenientes; (3) la deuda del campesino era tan grande que para saldarla se ofrece como esclavo; y (4) junto con la renta y los intereses, el comercio del trigo era otra fuente importante de ingreso para el rico $^{29}$.

En esta realidad maléfica, precisamente, Amós es "llevado por Dios" para que elabore y comunique un mensaje que honre el significado de su nombre. No solo debe poner por escrito el mensaje y su interpretación, sino que tampoco debe dejarse intimidar por las amenazas de la nobleza y las fuerzas represivas. La respuesta a la intimidación de Amasías muestra cómo Amós fue consistente con sus oráculos: "Yo no soy profeta ni hijo de profeta, sino un pastor y cultivador de sicómoros. Pero Yahvé me tomó de detrás del rebaño y me dijo: 'Ve y profetiza a mi pueblo Israel"' $(7,14-15)$. No se trata de predicar por predicar, ni de escribir por escribir, como si se tratase de una simple terapia retórica para el enojo, causado por el ansia de justicia que carcome por dentro al mensajero. Tampoco se trata de comunicar el sentir divino. Más bien, es tener conciencia de que el compromiso con Dios y con quienes más sufren es lo prioritario.

\subsection{El oráculo aldeano: condena, justicia y solidaridad esperanzadoras}

El mensaje de Amós refleja esa complicada realidad social, política, económica y religiosa. Y también tiene una respuesta con matices importantes, pero que, por razones obvias, debo resumir temáticamente ${ }^{30}$.

En primer lugar, Amós predica un mensaje de denuncia, aunque dirigido a varios auditorios. Los primeros destinatarios, en orden de aparición, son algunas naciones enemigas de Israel, que han cometido varios actos inmorales, los cuales merecen el repudio y el castigo divino aun cuando no forman parte del pueblo

28. B. Lang, "The Social Organization of the Peasant Poverty in Biblical Israel", op. cit., pp. 47-52.

29. Ibid., pp. 53-58.

30. Un análisis de la estructura y del contenido de Amós, en P. R. Andiñach, "Amós: memoria y profecía", op. cit., pp. 209-301; H. Reimer, "Agentes y mecanismos de opresión y explotación en Amós”, op. cit., pp. 153-168; y A. F. Botta, Los doce profetas menores, Minneapolis: Augsburg/Fortress, 2006, pp. 41-58. 
israelita y quizás nunca tuvieran acceso al mensaje de Amós. En segundo lugar, Amós se dirige a la clase dirigente israelita, y luego, también a Judá. Al igual que la profecía de Oseas, los destinatarios de Amós son los gobernantes, los terratenientes, los funcionarios, los sacerdotes y los ancianos ${ }^{31}$. Es decir, todos aquellos que, en virtud de su posición de privilegio y poder, habían generado riqueza y se beneficiaban de ella, pero a costa del sacrificio de la clase subalterna. Junto a Miqueas e Isaías, Amós forma parte de una tradición del profetismo radical. Sin embargo, aun cuando el mensaje del profeta está dirigido directamente a las cúpulas del poder, en definitiva, pretende llegar a los oprimidos para reiterarles que Dios está de su lado. La idea es fortalecerlos y cultivar en ellos la confianza en el Dios de la alianza, a pesar del sufrimiento experimentado a manos de sus victimarios.

Esta denuncia solidaria tiene matices muy característicos. Comienza con una expresión de indignación y rechazo ante la situación de pecado generalizado. En su santo enojo y con ánimo de dar su merecido a los culpables, anuncia cómo "Ruge Yahvé desde Sión; desde Jerusalén lanza su voz: en duelo estarán los pastizales de los pastores, la cumbre del Carmelo se secará" $(1,2 ; 3,8)$. Los desplazados pueden contar con alguien que, como ellos, se indigna ante la injusticia. Además, nada escapa del conocimiento divino. Dios todo lo sabe - "Que yo sé que son muchas sus rebeldías y graves sus pecados" $(5,12)$. Por lo tanto, el dolor que ocasiona vivir en la diáspora no pasa desapercibido. Pero pese a su intensidad, los oráculos de Amós no incitan a la violencia, ni a la revolución armada. La venganza pertenece a Yahvé ${ }^{32}$. Aun así, la denuncia del profeta tiene poder revolucionario.

No obstante, la acusación profética, que expresa la furia divina, no se presta para fines nacionalistas o etnocentristas, pues trata el pecado sin discriminación alguna. Israelitas o no, todos son reos de castigo. Así, Amós condena los delitos cometidos por las naciones paganas vecinas y anuncia el aciago juicio divino, que sobrevendrá a los responsables $(1,1-2,16)$. La inmoralidad, manifiesta en la opresión de los pueblos conquistados, los crímenes y las barbaridades cometidas contra los más débiles no pueden quedar impunes ante los ojos de Yahvé. El juicio es definitivo contra Damasco (1, 2-5), Gaza (1, 6-8), Tiro (1, 9-10), Edom (1, 11-12), Amón (1, 13-15) y Moab (2, 1-3). También contra los responsables actuales del desplazamiento forzado de los pueblos, cuyo sufrimiento los deja indiferentes.

Israel y Judá tampoco escapan al juicio de Yahvé. El reino del sur tuvo en poco la ley de Yahvé y desobedeció sus estatutos, por lo tanto, Dios le dará su merecido, en su momento $(2,4-5)$. Sin embargo, la peor parte se la lleva el reino

31. J. Bright, La historia de Israel, op. cit., p. 310.

32. Ibid., p. 314. 
del norte. La denuncia de Amós abarca la inmoralidad, en términos amplios, y la adopción de prácticas religiosas cananeas $(2,8-9)$. Han pasado por alto cómo Dios los ha guiado y protegido a lo largo de la historia (2,10-11). Violentan las instituciones divinas del nazareo y el profetismo. Son piedra de tropiezo de "los nazareos dedicados al servicio de Dios" e impiden el trabajo de los emisarios divinos $(2,12)$. Asimismo, el mensaje condena el paganismo infiltrado en el pueblo, "los altares de Betel" (3, 14; cf. 7, 9) y la adoración de Moloc y Quiún $(5,26)$.

No obstante, dadas las circunstancias y el contexto del libro, el mensaje principal del profeta denuncia de manera abierta y contundente la injusticia contra los pobres, ya sean ciudadanos, residentes o extranjeros desterrados. En lugar de la injusticia, debería fluir "el juicio como agua, la justicia como un torrente inagotable" $(5,24)$. La magnitud de la opresión y la violencia cometida en Samaria es descomunal $(3,9)$. El bien se ha ausentado, y en su lugar, en los palacios han imperado la rapiña y el despojo $(3,10)$.

El abuso brutal justifica el juicio contra el pueblo de Israel, cuyo castigo es inminente. Dios destruirá Samaria, capital del reino del norte, por causa de los ricos que se han beneficiado del dinero arrebatado al pobre. Su condición es igual a la de los países paganos $(6,2)$. Yahvé aborrece la riqueza de Jacob $(6$, 8), no tanto por la posesión de abundantes bienes, sino por la forma como han sido obtenidos, esto es, por medio de la opresión y el quebrantamiento de los humildes $(4,1)$. Las "vacas de Basán" - las mujeres de "la alta" sociedad- serán capturadas y convertidas en vasallas de Asiria por su pecado contra los pobres $(6,14 ; 7,11.17)$. Israel los ha ofendido y les han impuesto pesadas contribuciones de trigo. No gozarán de las casas construidas, ni de las viñas que han logrado a sus expensas $(5,11)$. En un tono muy emotivo, el profeta teme por el destino de los privilegiados y exclama, “iAy de los que se sienten seguros en Sion, y de los que están confiados en la montaña de Samaria, los notables de la capital de las naciones a los que acude la casa de Israel!" $(6,1)$, porque serán llevados en cautiverio. El reino del norte caerá en manos de los asirios: "Pues he aquí que yo suscitaré contra ustedes, casa de Israel [...], una nación que los oprimirá" $(6,14)$. Paradójicamente, la dispersión y la vida fuera del hogar son aquí parte del castigo o de la venganza divina.

Sorprende que Dios siempre haya concedido su gracia al pueblo para que enmendara sus errores. Pero este no aprovechó las muchas y reiteradas oportunidades para volverse a Dios y abandonar las prácticas injustas. No se arrepintió. Entonces, cómo no condenar el desaire del pueblo a los actos de buena voluntad $^{33}$. "Por eso, así voy a hacer contigo, Israel, y porque esto voy a hacerte,

33. El uso reiterado de la expresión "y no se volvieron a mí" $(4,6,8,10,11)$ enfatiza la necesidad de "regresar" (F. Brownet al., A Hebrew and English Lexicon of the Old Testament, op. cit., p. 997) a Dios y abandonar la vida inmoral del pueblo. Este juicio 
prepárate, Israel, a afrontar a tu Dios" $(4,12)$. A pesar de ello, Dios hace una nueva llamada para que cambie de conducta. Pide un cambio radical, abandonar la inmoralidad por la justicia. "Búsquenme a mí y vivirán" (5, 4.5.14-15; $c f$. v. 6). De lo contrario, el juicio divino aguarda a quienes persistan obstinadamente en no cambiar su estilo de vida. Yahvé permitirá que el reino de Asiria "oprima" al pueblo de Israel, así como este lo ha hecho con los pobres. Pagará por sus iniquidades. Una especie de ley karma se cumple en el mundo de significados, creado por el profeta, jel que oprime será también oprimido!

No obstante, los líderes del pueblo no parecen haber tenido conciencia de sus crímenes. Y si la tuvieron, no hicieron nada al respecto, sino que prefirieron seguir con su religión para acercarse al Dios del pacto. De esa forma, separaron la adoración de la vida cotidiana e hicieron caso omiso de la conducta ética. Sin embargo, Amós y los otros profetas no soportan ese culto. Buscar a Dios no significa participar en rituales, como si eso pudiera ocultar o suavizar el abuso de poder contra los pobres y la falta de solidaridad para con los desterrados. La vida del templo y la de la calle van de la mano. El culto a Dios y el servicio al prójimo no se excluyen. Dios rechaza la religiosidad y favorece la integridad y la coherencia $(5,21-25)$. La espiritualidad distorsionada, a conveniencia o irrelevante, debe dar paso a una espiritualidad integral. Nuestras comunidades de fe, que tienden a ser demasiado religiosas, harían bien en atender esta indicación divina.

Paradójicamente, a pesar de la dureza de su oráculo, Amós concluye su mensaje con un tono de esperanza y con una muestra de la misericordia divina. El epílogo del libro promete la restauración del reino davídico $(9,11-15)^{34}$. A pesar de los delitos de los israelitas, llegará el día en que los expatriados retornarán a la tierra, la utopía de un final feliz. Este mensaje se dirige a la comunidad de emigrantes, que busca un nuevo hogar.

El día aquel yo levantaré la cabaña de David ruinosa, repararé sus brechas y restauraré sus ruinas; la construiré como en los días de antaño, para que hereden lo que queda de Edom y de todas las naciones sobre las que se ha invocado mi nombre, oráculo de Yahvé, que así lo hará. He aquí que vienen días -oráculo de Yahvé- en que el arador empalmará con el segador y el pisador de la uva con el sembrador; destilarán mosto los montes y todas las colinas se derretirán. Entonces, haré volver a los deportados de mi pueblo Israel; reconstruirán las ciudades devastadas, y habitarán en ellas, plantarán vino y beberán su vino; harán huertas y comerán sus frutos $(9,11-14 ; c f$. vv. 8-9).

divino había sido puesto de manifiesto en muchas ocasiones, a lo largo del peregrinaje histórico del pueblo. Dios llama a abandonar aquellas prácticas que oprimen y a someterse a la ley de Dios.

34. J. G. Thomsony J. A. Motyer, “Amos, Book of”, op. cit., p. 44. 
El mensaje de Amós es, sin duda, una apasionada crítica contra las transgresiones del pueblo, en sus diversas concreciones: social e individual, estructural y coyuntural, religiosa y económica. Comunica el juicio divino, en represalia por haber abandonado la fe original de Yahvé, expresada en la alianza mosaica, y por la inmoralidad de la conducta con "la clase baja", israelita o de otras naciones. Asimismo, es un mensaje que llama a cambiar de vida. Al final, es un mensaje de esperanza para el resto que sí es fiel.

\section{El desplazamiento forzado: un contexto ético-teológico de desplaza- miento global}

A continuación reinterpreto a Amós desde la experiencia de comunidades pobres, en un contexto de expatriación, migración, exilio o diáspora, con la idea de que el análisis y la reflexión nos lleven a una praxis en la que Dios y nosotros trabajemos en equipo.

\subsection{Coyunturas persistentes de desafíos enormes}

El "darse por enterado" de la experiencia de la comunidad desplazada y empobrecida, mediante el análisis de sus causas, relaciones y complejidades, tiene un carácter instrumental. Es necesario comenzar a caminar.

Nuestros pueblos, como los de la Biblia, están en constante movimiento. Se estima que "migrantes internacionales" ascendían a 232 millones en 2013, equivalentes al 3.2 por ciento de la población mundial. La mitad de ese total ha luchado por rehacer su vida en Estados Unidos (45.8 millones), Rusia (11 millones), Alemania (9.8 millones), Arabia Saudita (9.1 millones), Emiratos Árabes Unidos (7.8 millones), Gran Bretaña (7.8 millones), Francia (7.4 millones), Canadá (7.3 millones), Australia (6.5 millones) y España (6.5 millones). La mayoría de emigrantes proviene de Asia (19 millones viven en Europa, 11 millones en América del Norte y 3 millones en Oceanía). América Latina y el Caribe le siguen de cerca con unos 26 millones, residentes en América del Norte. Todas esas sociedades ven y tratan al inmigrante como "forasteros" 35 .

En 2012, la persecución, el conflicto armado, la violencia, los abusos de los derechos humanos y los desastres naturales obligaron a 43.7 millones de personas a abandonar su hogar en todo el mundo. Unos 15.4 millones de ese total son refugiados, 937,000 solicitan asilo y 28.8 millones son "desplazados internos". La mayoría de estos últimos se encuentran en África subsahariana (10.4 millones), seguida por América Latina (5.8 millones). A partir de la década de 1990, Colombia tiene entre 4.9 y 5.5 millones de desplazados internos. Se

35. Ver el informe de Naciones Unidas sobre migración global. Disponible en http://esa. un.org/unmigration/wallchart2013.htm. 
estima que el 80 por ciento de los casi 44 millones de desplazados reside en países como Pakistán (1.9 millones), Irán (1.1 millones) y Siria (un millón). Unos 4.8 millones de palestinos, equivalentes al 43.4 por ciento de la población palestina total, viven en condición de refugiados, en los territorios ocupados (Siria, Líbano y Jordania) ${ }^{36}$. En Estados Unidos residen entre 12 y 15 millones de latinoamericanos o hispanos indocumentados.

Conviene recordar que la población desplazada experimenta todo tipo de vejaciones en los países de tránsito. Las organizaciones que prestan servicio a los migrantes alrededor del mundo apelan insistentemente a nuestra conciencia y nos recuerdan que la vida del migrante puede ser muy difícil, a veces un "infierno" ${ }^{37}$. Muchos individuos, grupos y estructuras, en palabras de Amós, "los que pisan la cabeza de los débiles, y el camino de los humildes tuercen" $(2,7 ; c f .8,4)$, merecen ser increpados: " $i$ Ay de los que cambian en ajenjo el juicio y tiran por tierra la justicia" $(5,7 ; c f .6,12)$, y los "opresores del justo, que aceptan soborno y atropellan a los pobres en Puerta!" $(5,12)$.

A millones de inmigrantes, sobre todo, a los refugiados, les cuesta mucho conseguir empleo en el país de acogida por carecer de documentos y porque regularizar su estatuto migratorio es casi imposible. Aquellos con suerte consiguen un empleo mal pagado y sin beneficios laborales. Al igual que en tiempos bíblicos, muchas veces les retienen el salario o les pagan menos de lo acordado ${ }^{38}$. Los sindicatos no los incorporan en la negociación laboral, ni defienden sus derechos, pese a que los inmigrantes generan capital interno y externo. En casos extremos, sus derechos constitucionales y humanos son violados. Su vulnerabilidad, como en tiempos de Amós, los convierte en presa fácil de la extorsión, el fraude, el robo, la violencia, la violación, la explotación sexual y el crimen de odio. Obligados a vivir en la clandestinidad, guardan silencio. Mienten para sobrevivir y no denuncian los delitos de los que son víctimas por miedo a la cárcel o a la deportación. Tal como diría Amós, en su "prudencia" no abren la boca, porque "es hora de infortunio" $(5,13)$.

36. Ver United Nations High Comissioner for Refugees (UNHCR), The State of the World's Refugees, UNHCR, 2012. Disponible en http://www.unhcr.org/4fc5ceca9. html.

37 Ver, por ejemplo, el análisis y las resoluciones sobre este tema de la organización mundial The People's Global Action on Migration, Development and Human Rights, disponible en http://hld2013.gcmigration.org/media/pga-2013-declaration-recommendations/; también R. Delgado Wise, H. Márquez Covarrubias y R. Puentes, Elementos para replantear el debate sobre migración, desarrollo y derechos humanos, México D. F.: Red Internacional de Migración y Desarrollo, 2010; E. G. Ferris, Uprooted! Refugees and Forced Migrants, Nueva York: Friendship Press, 1998.

38. Por ejemplo, Dt 24, 14-15; Lv19, 13; Job 7, 1-2; 24, 10; 31, 13.38-40; Pr 3, 27-28; Sir 7, 20; 31, 4.22 (o 34, 21); Tb 4, 14; Jr 22, 13; Mal 3, 5; Test Job 12; Mt 20, 8; Stg 5, 4. 
Los desterrados, por lo general, son considerados como "chivos expiatorios". Se les responsabiliza de las crisis económicas y sociales y también de algunas epidemias. En los campos de refugiados, la depresión, el hambre, el frío y la incertidumbre acosan a muchas familias, que viven en un limbo social. No obstante pagar impuestos, a muchos inmigrantes se les niega el acceso a los servicios de salud, vivienda y educación. Normalmente son criminalizados y se los tacha de "ilegales" o "terroristas". A diario son acosados, segregados, encarcelados y deportados, lo cual afecta el bienestar familiar. Mujeres y niños se llevan la peor parte. En algunos países, se lanzan campañas para negar la ciudadanía a los niños nacidos de padres extranjeros. A los forasteros que se esfuerzan por alcanzar un mejor nivel de vida, se los obliga a cruzar la frontera para trasladar droga o prostituirse. En la sociedad de acogida son víctimas constantes de prejuicios racistas, de xenofobia, del estereotipo, de homofobia y de otras muchas formas de abuso y exclusión. Pese a todo ello, estos grupos, gracias a su resistencia, contribuyen a desarrollar no solo la economía del país donde intentan radicarse, mediante su trabajo y consumo, sino que también la economía de su país de origen, mediante el envío de dinero. El Salvador, México y Guatemala encabezan la lista. Paradójicamente, los pobres, de su pobreza, dan a otros pobres.

¿Qué hacer ante desafíos de tal magnitud? ¿Qué posición adoptar ante una sociedad donde la acumulación del capital es el gran dios, el placer desmedido su consorte y la indiferencia su modus operandi? ¿Nos atreveríamos a vociferar con Amós: “¿Que yo sé que son muchas sus rebeldías y graves sus pecados!”? $(5,12)$.

\subsection{Movilidad obligada, comunidades dislocadas y vocación profética}

Cuando leemos a Amós a través del dolor de la expatriación y la vida en cautiverio, es obvio que su mensaje y su ejemplo nos invitan a articular una teología y un ministerio que denuncie las concreciones actuales de la injusticia, unas concreciones diabólicas y demoniacas. Así, pues, nos mueve a sopesar críticamente las situaciones que empujan a millones de comunidades a emigrar. Por consiguiente, es necesario oponerse al neocolonialismo, a la invasión, al sometimiento de los pueblos más débiles y a las barbaries, mediante las cuales se enriquece un reducido grupo, al amparo del mercado global. Sin recurrir al estereotipo y con autoridad moral, esto significa poner en evidencia los pecados de nuestras Damasco, Gaza, Tiro, Amón y Edom (1, 3-15). Asimismo, supone resistir la ideología "del placer por el placer", promovida por la cultura encallecida e idólatra de la abundancia económica y material. Aquellos que en sus fortalezas acumulan "el fruto de la violencia", ciertamente, no actúan con rectitud $(3,10)$.

En este sentido, es necesario ir más allá de la contemplación y la mística. No debemos conformarnos con predicar "una religiosidad virtual". Dios aborrece el culto insensible a la necesidad del otro, que sirve de guardia para esconder el 
crimen cometido en su contra $(2,8 ; 4,4-5 ; 5,21-23 ; 8,5.10)$. La lectura de Amós desde la realidad actual nos invita a derribar los muros que dividen "lo sagrado" de "lo profano". La fe cristiana es, por definición, una fe política y ética, pues se nos da y la profesamos en la historia, en particular, en relación directa con las necesidades de los demás. En cuanto aprehensión de las realidades últimas, la fe es también compromiso de diaconía con la cauda y los sueños de quienes exigen y se merecen una vida justa y digna. Es vergonzoso limitar nuestro trabajo a lo "espiritual" cuando hay otras dimensiones de la vida que ameritan ser transformadas por el poder del Evangelio. No olvidemos que nuestra espiritualidad, para ser verdadera, debe abarcar la totalidad de la vida ${ }^{39}$. Indudablemente, necesitamos de hombres y mujeres que, sacados de la comodidad y de la apatía del rebaño por la revelación de Dios $(3,7)$, vayan y profeticen $(7,15)$. Y si el Señor habla, “quién no va a profetizar?” $(3,8)$.

La Iglesia está obligada a romper con el mundo de la ingenuidad, con el temor paralizante y con la complacencia intimista para no ser una marioneta del sistema predominante. No debemos dejarnos manipular por los modelos socioeconómicos ni por las ideologías políticas. Los valores del Reino deben definir nuestros pensamientos y opciones. La astucia y el análisis crítico de lo que nos circunda han de formar parte de nuestras virtudes. Nuestra fe no debe inclinarse hacia el orden establecido, sino que debe hacer una opción definitiva y abierta por el débil y el que sufre. Debe desafiar todo signo de muerte y afirmar todo vestigio de vida. Apropiarnos de nuestra realidad y de la causa de las comunidades marginadas y empobrecidas es un imperativo impostergable de nuestra misión. De lo contrario, nos podemos convertir en presa fácil de la anestesia manipuladora del sistema dominante y de su ideología, en particular, de la del mercado.

Es necesario comenzar por casa y crear alianzas con los grupos que defienden los derechos humanos y prestan asistencia al necesitado. Una fe consecuente con la voluntad de Dios, tal como la expresa Amós, comienza con el rechazo y la condena pública de los mecanismos de opresión. Pero la proyección transcultural y más exigente hacia fuera, desde la Iglesia local o la denominación cristiana, siempre con espíritu ecuménico, comienza por casa. De ahí que el ministerio profético posea una dimensión "hacia dentro" y otra "hacia fuera" de la comunidad creyente. El mensaje no es complaciente, ni favorece a nadie en particular. Comprende todas las dimensiones espaciales y temporales, la Iglesia y la no iglesia. El mensajero marginal de Tecoa denunció las injusticias dentro y fuera del pueblo y dentro y fuera del ámbito religioso.

39. Ver mis recientes artículos "La espiritualidad como encuentro integral de vida: apropiación hermenéutica del Salmo 15", Presencia Ecuménica, 76 (septiembrediciembre 2012), pp. 2-10; y "Del palabrerío a la vida íntegra y coherente: la religión según Santiago 1, 26-27”, Estudios bíblicos, LXXI, 2 (2013), pp. 271-294. 
En sentido estricto, esta vocación no es para todos. Ser profeta es un ministerio para el cual se es llamado. Es un carisma. Pero la labor profética no debe restringirse a "los especialistas en la materia", tampoco debe ser una actividad periférica del quehacer cristiano. La experiencia de Amós, reinterpretada como paradigma transcultural de fe y de vida desde la situación actual, no deja otra alternativa que transitar por el tortuoso sendero del profetismo, en un esfuerzo mancomunado. La marcada estratificación social y el consecuente distanciamiento económico entre pobres y ricos, ciudadanos y extranjeros, habitantes de la tierra y desterrados no es menos real y brutal en la actualidad que en la época del reino del norte. La pobreza y la marginación son parte de la desnuda realidad vivida por nuestros pueblos y contra la que se pronuncian las organizaciones no gubernamentales de todo el mundo. El ministerio de los líderes eclesiásticos, sin ánimo de sustituir ni de relegar a segundo plano la participación del creyente común, ha de ser protagónico, pero sin caer en el "profesionalismo clerical". Dios necesita hombres y mujeres sensibles a "los signos de los tiempos", que acepten la llamada divina a identificarse plenamente con los expatriados, tal como lo hizo este siervo de Dios. La Iglesia de las Américas está llamada a tener una presencia activa y una militancia cristiana a favor de quienes, sin culpa alguna, son obligados a emigrar dentro y fuera de sus fronteras nacionales. La situación nos obliga y la conciencia nos interpela.

Todo ministerio contracultural, como es natural, genera forzosamente una oposición, muchas veces, violenta. Releído ampliamente, el Evangelio también es una "mala nueva". Por lo tanto, debemos estar preparados para experimentar críticas, acoso, rechazo e incluso actos violentos, porque la cúpula y sus vasallos son "los que detestan al censor en la Puerta y aborrecen al que habla con sinceridad" $(5,10)$. En el destierro, las fuerzas del mal maltratan a los desplazados y a quienes exigen que sus derechos sean respetados. El trayecto que recorren no es un jardín de rosas. Conscientes de esta realidad, estamos llamados a ejercer un ministerio que confronte a los agentes del poder y denuncie sus andanzas. Es una lucha encarnizada contra los signos del antirreino de Dios, en sus múltiples concreciones históricas. El precio a pagar es elevado, pero la recompensa es mejor aún, a saber, la satisfacción de cumplir la voluntad de Dios y de haber prestado un servicio desinteresado al que más lo necesita. No debemos callar, pero tampoco debemos dejar de actuar. El éxito viene dado por las mismas acciones solidarias y no por criterios exclusivamente cuantitativos o cualitativos. Amós no escatimó esfuerzos. Por lo tanto, nosotros tampoco.

\section{Mediaciones prácticas}

La comunidad cristiana no está llamada a ser un “clon” de Amós. Eso sería caer en un malentendido. Su mensaje y su praxis no son acabados, ni universales. Las limitaciones son obvias. Criticar los males sociales del pueblo de Israel sin aludir a las naciones enemigas de este, concentrándose solo en el sufrimiento de 
los pobres y pasando por alto la dimensión sistémica y sin proponer soluciones prácticas es una aproximación que, por muy bíblica que sea, apenas penetra en el meollo de la cuestión. Asimismo, las apasionadas y gráficas palabras de Amós desprovistas de matices y actualización podrían pecar de irrelevancia o exacerbar ciertas crisis. No obstante algunas similitudes, los contextos son radicalmente diferentes. El trasplante acrítico y liberal está condenado al fracaso.

Las palabras, aun las solidarias, se las lleva el viento o solo llegan a ciertos oídos. Aun cuando el lenguaje es un medio muy poderoso para concientizar, objetivar y organizar el pensamiento, se queda corto cuando se convierte en un fin en sí mismo. Es necesario construir un discurso profético que medie lo que queremos decir sin necesidad de recurrir a la humillación del adversario y a la violencia contra él. A veces, el lenguaje crudo, gráfico e incluso agresivo, pero con una circulación limitada, puede servir de catarsis para desahogar nuestros sentimientos reprimidos - como parte de una terapia grupal-, fortalecer las relaciones internas y concretar nuestras propias perspectivas. Sin embargo, conviene ser cautelosos. "Rugir como león" ante los victimarios y llamar las cosas por su nombre se comprende $(1,2)$. Pero referirse a ellos como "vacas de Basán" $(4,1)$ pudiera no ser la estrategia más eficaz para promover el cambio de actitud. Al apropiarnos de la causa de los expatriados, necesitamos una buena dosis de sabiduría para lidiar con la fuerza que las palabras llevan en sí mismas y generan.

Obviamente, la participación activa en movimientos que promueven la mejora social debe complementar y validar el discurso profético bien pensado. Aun el análisis concienzudo, por muy preciso e incisivo que sea, no es más que un medio al cual debemos recurrir para mejorar la condición de vida de los desamparados y los desterrados, mientras creamos modelos socioeconómicos de cooperación y desarrollo sostenido. Salvo contadas excepciones, las iglesias tienen mucho por hacer, pues su aproximación es todavía "conservadora" respecto a la lucha social y su visión del mundo es intimista y espiritualista. Tristemente, más que ofrecer una solución, siguen siendo jueces y parte del problema.

La abierta condena de la explotación y la opresión, una fuerza de concientización, debe ser seguida por una teología de la migración, fundamentada en la praxis de gestos concretos y difundida a través de las redes sociales (Internet, Twitter, Facebook, blogs, etc.), y también por medio de artículos, editoriales, ensayos y libros. Suele decirse que los medios de comunicación social han sido determinantes en el reciente despertar de pueblos como los de Turquía, Egipto, Grecia y Siria. Asimismo, debemos hacer alianzas estratégicas con grupos de base y ser parte de los procesos de mejoras sociales. La visibilidad y reiteración de acuerdos internacionales que defiendan y promuevan los derechos humanos y la reformulación de la legislación migratoria para superar al paradigma estricto de "la seguridad nacional" y del "desarrollo económico neoliberal", debe figurar en nuestra agenda pastoral. Debemos respaldar los acuerdos de cooperación 
económica con países en vías de desarrollo, porque reducen la presión para que la población no abandone su tierra. La política migratoria represiva y restrictiva en los países de tránsito y destino debe ser rechazada, pues el movimiento de los pueblos es un fenómeno natural y es imposible contener aquello que es innato. En este caso, lo único que cabe es el acompañamiento con una fuerte dosis de compasión y humanidad. La demostración pacífica y de resistencia contra el mal es importante. También los servicios de asistencia legal a las comunidades empobrecidas que, en su afán por acoger al forastero, desarrollan modelos hospitalarios de integración y participación.

Ahora bien, contrario al papel de los desplazados y migrantes en el libro de Amós, estos deben ser sujetos de sus propias transformaciones y de los de otros grupos marginados. No deben ser simples receptores pasivos de la bondad de otros. Es necesario pensar en las necesidades de otras personas y luchar para satisfacerlas. Nuestros esfuerzos deben estar movidos por una ética de la reciprocidad, fundamentada en "la regla de oro". Podemos dedicar ciertos días del año para concientizar, servir y manifestarnos públicamente. De esta manera, daremos notoriedad a la causa de las comunidades expatriadas y dispersas alrededor del mundo. Asimismo, podríamos celebrar el Día Internacional del Migrante (18 de diciembre) y el Día Mundial de los Refugiados (20 de junio), sin olvidar las otras conmemoraciones de Naciones Unidas ${ }^{40}$.

Estas no son más que algunas propuestas prácticas. Ciertamente, ninguna erradicará todos los males sociales, pero nos pondrán en camino para "crear una cultura de paz", que acoja "al otro"41. Las recomendaciones de los organismos mundiales de migración son valiosas. Bien podemos respaldar sus esfuerzos, en lugar de seguir el mal ejemplo de quienes hacen daño a los más vulnerables, de los que critican, pero permanecen al margen y de quienes recurren a la plegaria con la idea de que Dios haga milagros.

\section{Dios, contradicciones éticas y responsabilidades compartidas}

La erradicación de las comunidades de emigrantes y las experiencias de exclusión en suelo extraño a partir de la reinterpretación de Amós tienen clamorosas contradicciones, sobre todo, respecto a Dios. El Dios de los oráculos de

40. Por ejemplo, el Día de los Derechos Humanos (10 de diciembre), el Día Internacional de la Mujer (8 de marzo), el Día Internacional de la Eliminación de la Discriminación Racial (21 de marzo), el Día Internacional del Trabajo (1 de mayo) y el Día Universal del Niño (20 de noviembre).

41. Sobre esta cuestión, pero desde el punto de vista de la religión, ver Religiones por la Paz, "Acogiendo al otro. Una visión multirreligiosa de la paz", 22 de noviembre de 2013. Disponible en http://www.rfp.org/sites/default/files/pubications/ Declaracion\%20de\%20Viena.pdf. 
Amós es inconsistente y contradictorio respecto al desplazamiento humano y el trato dado a los emigrantes y extranjeros en la diáspora.

Por un lado, y en correspondencia con la visión de otros pensadores del Antiguo Testamento (por ejemplo, Dt 28, 63-68; 2Re 24, 14; cf. 1 Cr 5, 41), "el Dios de Amós" expulsa, esclaviza y mantiene en cautiverio -o permite que esto suceda - a los enemigos de Israel y al mismo pueblo escogido. Se trata de una medida disciplinaria para hacer justicia ante las desviaciones morales. En el caso de Israel, quizás Dios actúa de esa forma para que su pueblo se vuelva al Dios de la alianza y recupere la fidelidad a la ley mosaica. El pueblo debe aprender de sus desatinos. Por eso, el rey y la élite del reino de Amón son exilados. Son castigados con el destierro por los crímenes cometidos contra las mujeres embarazadas de Galaad (1,13-15). La ira divina se ensaña con el reino del norte. Los asirios invadirán y destruirán Samaria y se llevarán sus riquezas $(3,11-12)$, pues Dios no tolera la explotación y la vida suntuosa resultado de la injusticia (3, 9-12). Las "grandes señoras" de la clase privilegiada serán empujadas "con garfios y arpones", saldrán por las brechas del muro y serán expulsadas a Hermón (4, 2-3). Guilgal también "será llevada cautiva, y Betel, reducida a la nada" $(5,5)$. Por causa de su idolatría, Dios mandará a los israelitas "al exilio más allá de Damasco" $(5,27)$.Quienes se alimentan del ocio y del lujo, que "la dulce vida" les ofrece, "marcharán a la cabeza de los desterrados, y así terminará el banquete de los holgazanes" $(6,7)$. Aun cuando el rey Jeroboam y su capellán Amasías piensan que Amós conspira contra la corona, este no se amedrenta, ni altera su mensaje. Se niega a complacer a la dirigencia. "Jeroboam morirá a espada" (7, 11a), pero también "Tu esposa se prostituirá en la ciudad, y tus hijos y tus hijas caerán a espada. Tu tierra será medida y repartida, y tú mismo morirás en un país pagano. E Israel será llevado cautivo lejos de su tierra" (7, 17; cf. 11b). En palabras más modernas, y quizás raras, Dios favorece la emigración y sus penurias.

Extrañamente, ese mismo Dios, por el otro lado, no libera a algunos pueblos de la opresión para ofrecerles una vida mejor, sino que también se pronuncia en contra del desplazamiento forzado y el maltrato de la comunidad invadida y tratada como extranjera. Así, por ejemplo, en solidaridad con los pueblos desterrados y vendidos como esclavos a Edom por los reinos de Gaza y Tiro, promete descargar sobre ellos el peso de su ira. “iPor los tres crímenes de Gaza y por los cuatro, seré inflexible! Por haber deportado poblaciones enteras, para entregarlas a Edom, yo lanzaré fuego a la muralla de Gaza, que devorará sus palacios” [énfasis mío] (1, 6-7). “Por los tres crímenes de Tiro y por los cuatro, seré inflexible! Por haber entregado poblaciones enteras de cautivos a Edom, sin acordarse de la alianza fraterna" [énfasis mío] $(1,9)$. El Dios de los israelitas también liberó a los filisteos y a los sirios y los sacó de Creta y Quir $(9,7 ; 2 R e$ 16, 9). Asimismo, repudia las políticas expansionistas de Amón y los desalmados crímenes contra las mujeres embarazadas de Galaad, todos ellos indefensos. Por eso, en justa represalia, el rey y la dirigencia política irán al destierro (1, 13-15). 
La emigración y los numerosos cuidados de Dios durante su peregrinaje hacia la tierra prometida subrayan la dimensión positiva del desplazamiento - si es que Dios es directamente responsable de ello. "Y yo los hice subir del país de Egipto y los conduje por el desierto durante cuarenta años para que poseyeran la tierra del amorreo" $(2,10)$, a pesar de la deslealtad y la ingratitud $(5,25)$. Sin embargo, conviene recordar que este proyecto a favor de Israel tiene consecuencias destructivas para aquellos que fueron desalojados injustamente de sus tierras y esclavizados. En su deslealtad, Israel se comportó como los descendientes de los etíopes (“Cus”) (9, 7a), pero aun así, Dios “los sacó de Egipto” (3, 1; 9, 7b). En su fidelidad incondicional, después del destierro, Dios promete llevar a Israel de regreso a la tierra de la que fueron expulsados, para nunca más ser "arrancados" de esa tierra que Él les obsequió (9, 11-15; cf. Za 10, 9; Sal 147, 2; Ne 1, 8-9; Is 49, 6; 2Ma 1, 29; Sal de 8, 34). En todos estos casos de exilio, Dios interviene, pero por una noble causa.

Esta doble caracterización de Dios, no exenta de complejidad, plantea cuestiones serias. ¿Está Dios en contra o a favor del desplazamiento masivo de las comunidades? ¿Es Dios responsable, directo o indirecto, de las deportaciones y los maltratos a los que muchas comunidades pobres son sometidas? ¿Qué papel juega en la creación de las situaciones de escasez o abundancia, que obligan a los pueblos a procurarse "los pastos verdes" que no encontramos en sus áridos hogares? ¿Cuándo "el éxodo forzado" de los pueblos es un acto de liberación o de castigo? ¿Cuáles son los criterios y qué certeza podemos tener? ¿Qué derecho tiene "Dios" para despojar a los pueblos de sus tierras y dárselas a unos "recién llegados", como en el caso de Israel, y para someterlos a sus designios? ¿Quién habla por las comunidades no israelitas, cuyos derechos y cuya dignidad han sido pisoteadas? ¿Y por qué razón deben pagar "justos por pecadores”, incluso las mujeres y los niños? ¿Cómo deben definirse la soberanía y la justicia divinas en relación con el desarraigo y la dispersión de las comunidades?

El diálogo con Amós se presta a otras preguntas que complican más la cuestión. ¿Será que el Dios de la Biblia, “creado a imagen y semejanza de los seres humanos" para legitimar sus creencias y acciones, no es totalmente real, sino una especie de "proyección" de las imperfecciones y ambigüedades de la finitud humana? De ser así, la cuestión se reduce a nuestra percepción de lo divino y no a Dios mismo. Pero lo que sabemos de ese Dios nos llega mediado por esa percepción, a la cual muchos llaman "revelación". Por el otro lado, ese Dios "construido" como personaje de historias sería más "como nosotros". Por lo tanto, más confiable y con quien podríamos identificarnos más fácilmente. Al igual que nosotros, siempre tendría la posibilidad de reivindicarse para ser más íntegro de la misma forma que nos exige integridad a nosotros. Y si me perdonan la osadía de continuar mi reflexión, ¿sería, entonces, irrespetuoso expresar nuestras inquietudes de esta manera tan honesta como brusca? ¿No sería mejor callar y no reprochar a Dios, pues Él es creador y soberano del universo, y nosotros no? 
La profundización en el sentir y actuar de Dios respecto a las comunidades expulsadas de su tierra natal y los abusos de que son víctimas implica "distorsiones". No es para menos, pues tanto Él como nosotros estamos insertos en un contexto de dispersión y fragmentación y ambos sufrimos sus contrariedades y ambigüedades. Evadir nuestra percepción de lo sagrado sería un error. Sería mucho más fácil reprimir nuestro sentir distorsionado con un "no sabemos" y confiar ciegamente. O peor aún, responsabilizar a Dios de lo malo y lavarnos las manos. Es el caso de quienes defienden a Dios o intentan explicar la naturaleza del bien y del mal, pero no hacen nada, o muy poco, para aliviar el dolor humano.

En términos prácticos, por qué no entablar un diálogo crítico con el Dios de Amós para pedirle cuentas de la misma forma que Él nos las pide a nosotros. Debemos trabajar más para crear una cultura del amor, de la justicia y de la paz, tanto en el país de origen de los emigrantes como en los de tránsito y los de destino. Nuestros esfuerzos deben orientarse a mitigar o eliminar las causas que empujan a los pueblos a moverse y el maltrato del que son víctimas en cualquier sitio. Una verdadera "relación de confianza" con Dios, o "relación de fe", debería abrir espacio para el intercambio honesto y abierto de ideas. De esa forma, será más difícil evadir nuestra responsabilidad ética con el mundo. Si Dios cuestiona nuestras vidas porque, en nuestra indiferencia y egoísmo, permitimos o contribuimos a crear condiciones injustas, ¿sería faltarle al respecto hacerlo "corresponsable" de lo que sucede en el mundo, ya sea que lo permita o lo cause, e invitarlo al mismo tiempo a "colaborar" con nuestros proyectos de liberación humana? ¿Por qué no trabajar hombro con hombro de manera que, antes que enjuiciarnos, defendernos, excusarnos o mantenernos al margen, acompañemos a quienes más sufren? Siempre asegurándonos de que actuamos de manera íntegra.

Así, pues, debemos hacer a un lado este enmarañado misterio y concentrarnos en aprovechar las oportunidades de la vida para caminar con "las comunidades en movimiento". Pensemos en lo que podemos, debemos y haremos para crear un mundo mejor. Nuestra denuncia y nuestra praxis deben orientarse a la construcción, juntamente con Dios, de condiciones de vida que nos hagan regresar a "la tierra" de la cual salimos para nunca más ser "arrancados" de ella $(9,15)$. Solo abriendo paso a la esperanza para "Que fluya, sí, el juicio como agua, la justicia como un torrente inagotable" $(5,24)$, tal como el vocero campesino del reino de norte lo visualizó e intentó concretar, sabremos que verdaderamente hemos sido "guiados por Dios". 